(IUCN, LC), Mediterranean gull Larus melanocephalus (IUCN, LC), and aquatic warbler Acrocephalus paludicola (IUCN, VU). The construction of the planned inland waterway could also result in a reduction of tourism and a consequent loss of income for local people.

GRZEGORZ GRZYWACZEWSKI (๑ orcid.org/0000-0003-11360768) University of Life Sciences, Lublin, Poland

E-mail grzegorz.grzywaczewski@up.lublin.pl

IGNACY KITOWSKI The State School of Higher Education, Chetm, Poland

\section{Conserving African biosphere reserves: a workshop on the valuation of ecosystem services in Man and the Biosphere Reserves}

In Bahir Dar, Ethiopia, on the shores of Lake Tana, a workshop for the valuation of ecosystem services in Man and the Biosphere Reserves was held on 13-17 May 2019. 'Evamab' is a 3-year research project funded by the Belgian Science Policy under an agreement with UNESCO's Man and the Biosphere programme, carried out by a consortium of Belgian and African research institutes and universities. The project aims to understand, apply and improve approaches for ecosystem services assessment in African Man and the Biosphere Reserves. It focuses on four Reserves, in Benin (Pendjari), Ethiopia (Lake Tana), Tanzania (Lake Manyara) and Uganda (Mount Elgon), reflecting a range of socioecological and biogeographical conditions, including savannah, Afro-montane and lacustrine systems, all of which are undergoing rapid anthropogenic changes.

Managing Biosphere Reserves requires socially and scientifically pertinent and robust approaches, especially in weak institutional contexts. The ecosystem services concept connects the programme's goals, activities and the associated stakeholders at local and global levels. Existing ecosystem services assessment tools have been categorized based on user-generated criteria collected through an iterative Delphi survey at the 2017 African Man and the Biosphere Reserves Network Meeting in Nigeria. A selection of tools for rapid assessment of ecosystem services has been tested and customized in the field. The interdisciplinary and cross-cultural approach to using and evaluating assessment tools allowed us to learn about the opportunities and pitfalls associated with the valuation of ecosystem services and informed the preparation of decision-support tools for a range of stakeholders in research, policy and practice.

During the workshop, c. 40 participants (Biosphere Reserve managers, scientists and policy makers) contributed to the design and contents of a UNESCO Manual for Management Based on Ecosystem Services in African Man and Biosphere Reserves. A participatory approach combining World Café (i.e. rotating tables) workshops, consensus building discussions and the sharing of field-based experiences in the four case studies and beyond was conducive to collecting expert input. The final version of the manual is due in January 2020, and a first draft is scheduled to be presented at the 2019 African Man and the Biosphere Reserves Meeting in Abidjan, Côte d'Ivoire, the 2019 Ecosystem Services Partnership World Conference in Hannover, Germany, and the 2020 IUCN Congress in Marseille, France. The participants agreed on a co-stewardship and research-based approach in the management of Biosphere Reserves, and the manual and derived products should appeal to both managers and decision makers. In the workshop, the opportunities of using ecosystem services as a tool were illustrated by payment for ecosystem services initiatives in Uganda, communitybased workshops held in Benin, Uganda and Tanzania, and willingness-to-pay studies conducted among communities surrounding Lake Tana and Pendjari Biosphere Reserves.

The valuation of ecosystem services in Man and the Biosphere Reserves 'Evamab' project aims to connect local managers and communities-who are the ultimate stewards of their social-ecological systems-and global beneficiaries of large-scale ecosystem services, such as carbon storage and climate stability, to the realities of the day-to-day management of African Biosphere Reserves. During a field trip on Lake Tana, participants experienced first-hand the challenge of the rapid expansion of the invasive, non-native water hyacinth Eichhornia crassipes, which locally hampers fisheries and livelihoods. A visit to a local Christian Orthodox monastery illustrated the importance of ancestral culture as a local ecosystem service (tourism revenues and conservation of sacred groves). Project updates are posted on the project website (biodiv.be/evamab) on a regular basis.

LUC JANSSENS DE BISTHOVEN (৫ orcid.org/0000-0002-95471563) and AnNe-Julie RochetTe and ERIK VerheYen Royal Belgian Institute of Natural Sciences, Brussels, Belgium E-mailljanssens@naturalsciences.be

TeWogBade JeAn-DidIER AKPONA Université d'Abomey-Calavi, Cotonou, Bénin

BRUNo Verbist and KoEN VANDERHAEgen Katholieke Universiteit Leuven, Leuven, Belgium

ZerubabeELI NatURINDA Busitema University, Uganda

SteVen VAN Passel Universiteit Antwerpen, Antwerp, Belgium

DAREGOt BeRIhun Bahir Dar University, Bahir Dar, Ethiopia

LINUS MUNISHI Nelson Mandela African Institution of Science and Technology, Arusha, Tanzania

JEAN Hugé Université Libre de Bruxelles, Brussels, Belgium; Hasselt University, Hasselt, Belgium; and Royal Belgian Institute of Natural Sciences, Brussels, Belgium 